of the prehistoric art within the caves at Altamira by Don Marcelino-more particularly by his dog, and especially by Maria, his 9-year-old daughter. It was this little girl who was the first to direct her gaze upwards, and thus become the discoverer of the glories of the "Sistine Chapel of prehistory". Altamirage is defined as "the facility for encountering unexpected good luck as the result of highly individualised action". It transcends the boundaries of serendipity in its role of personal action in chance.

The erudite and stimulating chapters which make up the final sections are psychological and philosophical in nature, and deal with such subjects as, for example, the creative personality. In an interesting fashion the author reviews the considerable literature concerning the anatomy of creativity. He emphasises, in a manner which merits the attention of all senior academics who dispense power and patronage, Dragstedt's essay "Who Killed Cock Robin" in which is described the gradual death of creativity in a researcher who becomes enmeshed in too many committees. In Dragstedt's words, "the early days in the laboratory are the golden years for many scientists. After he becomes known, the volume of mail, telephone calls, number of visitors, organisational activities, including committees by the dozen, and demands for lectures, reviews and community activities grow insidiously and will destroy the creativity of the scientist if unopposed".

Throughout his book Dr Austin recurringly mentions the part which the arts may have contributed to his scientific career. Music is there, and more particularly an almost obsessional, lifelong preoccupation with colour. It is tempting to believe that the author is, or was, a synaesthetic thinker, though he nowhere explicitly says so. Likewise he speaks of a reality familiar to some who have closely studied the phenomena of the body-image, and which the reviewer has never before seen expressed in print. According to Austin, "Even now, writing these lines, I retain a clear visual image of the scene at the desk where these ideas burst forth. This time, in a kind of mental double vision, I am both a participant in the process and a spectator hovering over a point about five feet up and ten feet directly to the rear." (My italics.)

The reviewer has nothing but admiration for Chase, Chance and Creativity, and confesses that Dr Austin is a man he would very much like to congratulate in person.

Macdonald Critchlev is Honorary Consulting Physician at the National Hospital. London, $U K$.

\section{Major flowering plant families}

\section{Peter D. Moore}

Flowering Plants of the World. Edited by V. H. Heywood. Pp. 335. (Oxford University Press: Oxford and London, 1978.) £7.95.

IT is an unusual experience to come across a book which demands unreserved praise; this one does. In both concept and execution this work is eminently laudable. It aims at providing a simple introduction to the major flowering plant families of the world; over 300 are described, so it approaches a comprehensive coverage.

The book commences with a brief introduction to the structure and biology of the angiosperms together with an outline of their evolutionary history and the criteria which are used in their classification. As the book is likely to attract a wide market outside the circles of academic botany, this is a very necessary section. Even within such circles it will prove a useful summary for students. It includes Stebbins' diagrammatic portrayal of evolutionary relationships within the flowering plants.

There follows a synopsis of classification in which families are arranged into their ten Orders. On the whole the Stebbins system is used, except where some small families are fused with closely related ones.

Technical terminology in plant morphology is, according to Heywood, one of the major obstacles for the amateur, which keeps him from the appreciation of much taxonomic botany. Undoubtedly he is right in this, and the provision of an illustrated glossary should go a long way towards demolishing this obstacle, especially as the attractiveness and clarity of the illustrations make it quite the most explicit glossary of its kind currently available.

The bulk of the text (300 pages) consists of a systematic treatment of the plant families. The description of each family includes an assessment of its distribution, both verbally and cartographically. The distribution maps are a unique feature of the book, which will prove particularly interesting to those interested in phytogeography. The verbal descriptions are necessary supplements; for example, although the family Magnoliaceae is found in southeast Asia and in North, Central and South America, $80 \%$ of the genera come from the former region. A map on its own could be misleading.

The diagnostic features of each family are then described, and here the use of technical terms for the sake of brevity will necessitate frequent use of the glossary. Major subdivisions within the family are then described and finally its economic value is considered. The latter is a source of much interesting information and includes medicinal, timber and horticultural uses.

Quite the most striking features of the book are the illustrations. Each family has a few characteristic members illustrated both by habit drawings and flower sections. Many of the illustrations are reproduced in a sepia monotone with certain parts, often the flower or fruit, picked out in full colour. It is impossible to convey in words how aesthetically pleasing and technically informative this form of representation has proved. It combines the clarity of a line diagram with the naturalness of a well-composed painting. Victoria Goaman, Judith Dunkley and Christabel King, together with the publishers, must be congratulated on a set of illustrations which are unsurpassed in current popular botanical literature.

It would be petty to dwell upon errors in the text; they are present, but fortunately scarce. For example, the primrose is referred to as Primula veris rather than $P$. vulgaris.

There are no comparable books which could compete with this one, either in quality of production or in price (at under $£ 8$ it must be rated a bargain). Older books, such as G. H. W. Lawrence's Taxonomy of Vascular Plants (Macmillan. New York, 1951), which have served generations of students, lack the fine illustrations and the distribution maps of Heywood's book. These features will also appeal to the very considerable amateur market in both Europe and North America.

This book is more than a textbook of taxonomy, it is a publication which will stimulate an interest in plants within any who open its covers. It is an item which all biologists should have on their bookshelves. Oxford University Press are to he congratulated on the production of a book which will be of great service to botany and which is a credit to British publishing.

Peter D. Moore is Senior Lecturer in Plant Sciences at King's College. University of London. UK. 